\title{
Erratum to: Scope for a small circumsolar annular gravitational contribution to the Pioneer anomaly without affecting planetary orbits
}

\author{
Guy S.M. Moore · Richard E.M. Moore
}

Received: 19 July 2013 / Accepted: 19 July 2013 / Published online: 31 July 2013

(C) Springer Science+Business Media Dordrecht 2013

Erratum to: Astrophys Space Sci

DOI 10.1007/s10509-013-1514-2

In Appendix A.1, for $0.01 \times 5^{\circ} \mathrm{AU}$, please read $0.01 \times$ $5^{n} \mathrm{AU}$.

The online version of the original article can be found under doi:10.1007/s10509-013-1514-2.

G.S.M. Moore $(\varangle)$ · R.E.M. Moore

9 West Avenue, Sandown, Isle of Wight, PO36 9LT, UK

e-mail: gsmm.physics@gmail.com

R.E.M. Moore

e-mail: remm.physics@gmail.com 